\title{
Secretory expression of the recombinant FGF-2 protein in Pichia pastoris carrying multiple copies of target gene
}

\author{
Le Kha Han*, Nguyen Cao Kieu Oanh, Nguyen Hieu Nghia, Nguyen Tri Nhan*
}

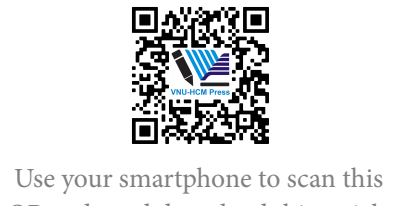

QR code and download this article

VNUHCM - University of Science

Correspondence

Le Kha Han, VNUHCM - University of Science

Email: Ikhan@hcmus.edu.vn

\section{Correspondence}

Nguyen Tri Nhan, VNUHCM - University of Science

Email: ntrnhan@hcmus.edu.vn

History

- Received: 2020-01-01

- Accepted: 2020-04-06

- Published: 2020-04-14

DOI : 10.32508/stdj.v23i2.1746

\section{Check for updates}

\section{Copyright}

(C) VNU-HCM Press. This is an openaccess article distributed under the terms of the Creative Commons Attribution 4.0 International license.

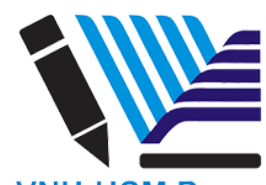

VNU-HCM Press

\begin{abstract}
Introduction: Fibroblast growth factor-2 (FGF-2) is a multifunctional protein that plays an important role in the regulation of proliferation, differentiation and migration of a variety of cells. The recombinant human FGF-2 (rhFGF-2) is currently used in stem cell culture, medicine and cosmetic products. In this study, we aim to produce secreted rhFGF-2 protein from a Pichia pastoris strain containing multiple copies of the $f g f-2$ gene to eliminate the disadvantages of intracellular expression systems. Methods: The recombinant Pichia pastoris carrying the fgf-2 gene was cloned by using homologous cloning method. The recombinant strains were screened by PCR reactions using specific primers for the target gene and the AOX1 promoter sequence. Moreover, the copy number of the $f g f-2$ gene inserted into the $P$. pastoris genome was identified by semi-quantitative PCR method. The secreted rhFGF-2 protein was collected in the induced BMMY medium at a final methanol concentration of $0.5 \%$, and purified by one-step heparin affinity chromatography. The quantity and biological activity of the purified protein were determined by competitive ELISA method and MTT assay on NIH-3T3 cell line, respectively. Results: Various recombinant P. pastoris clones carrying different copy numbers of the fgf-2 gene were obtained and categorized into 3 groups: the low copy strains (4-5 copies), medium copy strains (8-11 copies), and high copy strains (more than 20 copies). Among those strains, the 4-copy one produced the rhFGF-2 protein at the highest expression level. After purification, the purity of rhFGF-2 protein reached $98.8 \%$, and the recovery yield was $179.2 \mu \mathrm{g}$ of protein from $200 \mathrm{~mL}$ of flask culture (equivalent to $850 \mu \mathrm{g} / \mathrm{L}$ ). The purified rhFGF-2 protein showed similar biological activity on NIH-3T3 cell line with the commercial FGF-2 protein. Conclusion: The recombinant FGF-2 protein was successfully secretory expressed from Pichia pastoris, and successfully purified by only one-step chromatography.

Key words: basic fibroblast growth factor, quantification of gene copies, Pichia pastoris, heparin affinity chromatography
\end{abstract}

\section{INTRODUCTION}

Basic fibroblast growth factor, also known as fibroblast growth factor-2 (FGF-2), was first discovered in 1973. It plays a crucial role in bone formation ${ }^{1}$, regulation of tissue repair ${ }^{2-4}$, wound healing ${ }^{5}$, and angiogenesis ${ }^{6}$. Currently, it is used in stem cell culture, medicine and cosmetics. To enhance the interaction between FGF-2 and its receptors, FGF-2 needs to bind to heparin or heparan sulfate proteoglycans ${ }^{7,8}$. The single chain of this protein contains 146 amino acids ( $\mathrm{pI}=9.6$ ) and molecular weight is approximately $18 \mathrm{kDa}$. Specifically, it is easily expressed in prokaryote systems since the post-translational modifications and intra-disulfide bond are not required for its functionality. Up to now, FGF-2 has been expressed in various expression systems as intracellular protein $^{9-12}$. However, these expression systems are not actually utilized since they have difficulty in disrupting the cells and purifying the target protein. The difficulties of intracellular expression systems have been mainly caused by taking time in collecting protein inside the cells and a lot of contaminating proteins of the host cells. Most of recombinant FGF-2 protein from intracellular expression systems need to perform 2-step purification in order to reach the expected purity of the desired protein, or tag cleavage step with fusion tag protein ${ }^{9,12}$. Hence, this study focused on using a secretory protein expression system of $P$. pastoris in order to overcome these disadvantages.

The methylotrophic yeast $P$. pastoris is the most common secretory heterologous recombinant protein expression system. This strain has the ability to secrete target proteins more efficiently than Saccharomyces cerevisiae does, due to a strong promoter, tight regulation, and large size of exosomes ${ }^{13,14}$. Wild-type $P$. pastoris $\mathrm{X} 33$ strain possesses 2 genes, AOX1 and AOX2, which encode for the methanol metabolism protein. In particular, the AOX1 gene is regulated by the AOX1 promoter, which is a strong promoter. 
To enhance the yield of recombinant proteins in $P$. pastoris, the use of the AOX1 promoter is one of the most common strategies. There are two different types of homologous recombination-mediated insertion, which are (i) ends-in insertion which leads to additive insertion of the target gene and (ii) endsout insertion which facilitates the replacement of the native AOX1 gene ${ }^{15}$. The replacement of the AOX1 gene greatly reduces the ability of the host strain to consume methanol, and only one copy of the target gene is inserted into the P. pastoris genome, which can lead to low expression levels of the recombinant protein. Many studies have shown that the existence of multiple copies of recombinant genes can achieve better target protein expression levels ${ }^{16-18}$. In addition, for this strain, it has been demonstrated that the expression level in optimized fermentation scale of the strain could be higher than shake-flask scale (approximately 16.4 -fold) with simple and cheap culture medium ${ }^{19}$. Thus, $P$. pastoris is a suitable host cell for industrial scale. Besides, the purification of secreted recombinant protein from $P$. pastoris might be easier than other systems since most of native secreted proteins have a $\mathrm{pI}$ lower than $6.0^{20}$. In a previous study, FGF-2 was successfully expressed and purified in $P$. pastoris $^{21}$. The volumetric productivity of the purified FGF-2 (more than $94 \%$ of purity) reached 150 $\mathrm{mg} / \mathrm{L}$ with optimized shake-flask culture condition and two-step purification; this result was 1.5 times higher than the yield of rhFGF-2 protein expressed in E. coli $^{9}$. However, this study did not investigate the effect of target gene copy on recombinant protein expression.

Therefore, in the present study, we constructed the recombinant Pichia pastoris X33 carrying multiple copy $f g f-2$ gene and further investigated the correlation between gene copy number and expression level of extracellular rhFGF-2 protein in Pichia pastoris. With the aim of shortening the downstream process and enhancing purity, the purification of the rhFGF-2 protein was experimentally performed with a 1-step purification strategy using heparin affinity chromatography. The biological activity of purified rhFGF-2 was evaluated on the NIH-3T3 cell line.

\section{MATERIALS-METHODS}

\section{Gene, strains and plasmids}

The gene encoding for FGF-2 was optimized from an origin sequence (UniProtKB - P09038) and then generated by overlap extension PCR method. E. coli host strain DH5 $\alpha$ (Thermofisher Scientific, California, US) and wild-type P. pastoris X33 (Thermofisher
Scientific) were used for cloning and gene expression experiments, respectively. In addition, plasmid pPICZ $\alpha$ A (Thermofisher Scientific) was used for cloning and expression studies.

\section{Cloning of pPICZ $\alpha A / f g f-2$ plasmid in E. coli}

The cDNA encoding for FGF-2 protein was amplified by PCR (Biorad, California, US) with specific primers FG-F and FG-R (primer sequences are shown in Table ?? - Supplementary document). The cDNA was cloned into the pPICZ $\alpha$ A plasmid under the control of the AOX1 promoter by eClone-homologous cloning kit (Laboratory of Molecular Biotechnology, Viet Nam National University - University of Science, Viet Nam). The pPICZ $\alpha \mathrm{A} / f g f-2$ plasmid was transferred into E. coli DH5 $\alpha$ and incubated in LB-Zeocin medium (Himedia, Mumbai, India) overnight. The transformants were screened by PCR using $f g f-2$ gene specific primers. The plasmid of randomly chosen positive colonies was extracted, purified by alkalineSDS lysis method, and verified by PCR using the primers AOX-F/FG-R and primers AOX-F/AOX-R (primer sequences are shown in Table ?? - Supplementary document). Afterwards, the recombinant vectors $\mathrm{pPICZ} \alpha \mathrm{A} / f g f-2$ were confirmed for the correct open reading frame by AOX1 promoter sequence analysis.

\section{Cloning of pPICZ $\alpha$ A/fgf-2 plasmid in P. pas- toris}

In the present study, $P$. pastoris X33:: $\mathrm{Mut}^{+}$wild type was used for cloning. The plasmid of positive $E$. coli colonies was extracted by alkaline-SDS lysis method, then transferred into $P$. pastoris $\mathrm{X} 33$ by electroporation (Biorad, California, US). Plasmid pPICZ $\alpha \mathrm{A} / f g f$ 2 was integrated into host genome through recombinant homologous site on the AOX1 promoter sequence. To improve the recombinant homologous yield, the plasmid pPICZ $\alpha \mathrm{A} / f g f-2$ was linearized by SacI enzyme (Thermo Fisher Scientific). The transformants were selected on YPD-zeocin medium (Himedia) and further identified by PCR using the primer set of FG-F and FG-R. To investigate insertion type, the genome of recombinant $P$. pastoris was extracted and PCR was performed with the primer set of AOX-F and AOX-R.

\section{Indirect quantification of recombinant fgf- $\mathbf{2}$ gene copy number in $\boldsymbol{P}$. pastoris}

The genome of recombinant $P$. pastoris strains was extracted to perform PCR. The relative quantification of recombinant $f g f-2$ gene copy number was indirectly 
quantified by PCR products and compared with the standard curve. Wild-type P. pastoris X33:: $\mathrm{Mut}^{+}$was used as a genome concentration standard. The number of gene copies was calculated by the ratio of the brightness of target gene band $(\mathrm{Y})$ and AOX1 gene band (X) (Figure 1). The results of PCR were analyzed by electrophoresis and the brightness of band was determined by ImageJ software.

\section{Shake-flask expression in P. pastoris}

A colony was picked up from the plate and overnight pre-cultured in $10 \mathrm{~mL}$ YPD-zeocin medium at $30^{\circ} \mathrm{C}$ and $250 \mathrm{rpm}$. Then, the culture was transferred into $10 \mathrm{~mL}$ BMGY medium (Himedia) with a ratio of $1: 10(\mathrm{v} / \mathrm{v})$. When $\mathrm{OD}_{600}$ reached $2.0-6.0$, the cells were harvested by centrifugation at $5000 \mathrm{rpm}$ ( $4^{0} \mathrm{C}$ for 5 minutes), and the pellet collected. After that, the pellet was resuspended in $30 \mathrm{~mL}$ BMMY medium. In order to induce the expression of the $f g f$ 2 gene, methanol (Xilong Scientific, Shantou, China) was added every 24 hours to a final concentration of $0.5 \%(\mathrm{v} / \mathrm{v})$. After 72 hours, the supernatant of the culture was collected by centrifugation at $5000 \mathrm{rpm}$, $4^{0} \mathrm{C}$ in 30 minutes. The rhFGF-2 expression was determined by SDS-PAGE gel (Himedia) using silver staining (Xilong Scientific) and competitive ELISA (Thermo Fisher Scientific).

\section{Purification of rhFGF-2 by heparin-affinity chromatography}

Considering the isoelectric point and specific affinity of the target protein, heparin-affinity chromatography was chosen to purify rhFGF-2. The HiTrap Heparin HP $5 \mathrm{~mL}$ column (GE Healthcare, Chicago, US) was equilibrated with $25 \mathrm{~mL}$ Buffer A (20 mM Tris$\mathrm{HCl}$ (Biobasic, Toronto, Canada), $\mathrm{pH}$ 7.5) at a rate of $5 \mathrm{~mL} / \mathrm{min}$. Subsequently, the supernatant was applied to the column at a rate of $5 \mathrm{~mL} / \mathrm{min}$. After that, the column was washed with $50 \mathrm{~mL}$ Buffer A. The rhFGF2 protein was eluted by stepwise method with a variety of Buffer B (20mM Tris-HCl, pH 7.5, 2M NaCl (Scharlau, Barcelona, Spain)) concentration. The purity and yield of purification were determined by SDS-PAGE using silver staining, ELISA, and Gel Analyzer 2010a software.

\section{Qualification of rhFGF-2 protein by SDS- PAGE and Western blotting}

SDS-PAGE method was performed using a $15 \%$ gel according to the method of Laemmli. To detect the target protein expression, proteins in the gel were ran with low range protein marker (GE Health Care) and stained with $0.03 \%$ silver nitrate.
Western blotting was performed to verify the presence of the rhFGF-2 protein. The in-gel protein after running SDS-PAGE was transferred onto nitrocellulose membrane (GE Health Care) and probed with mouse anti-human FGF-2 IgG (Sigma-Aldrich, Missouri, USA). The anti-mouse horseradish peroxidase (Sigma-Aldrich) was used as a secondary antibody. Detection of rhFGF-2 was carried out using Supersignal West Pico Chemiluminescent Substrate (Thermo Fisher Scientific) and ImageQuant LAS 500 (GE Health Care).

\section{Quantification of rhFGF-2 protein by com- petitive ELISA}

The expression level of recombinant protein was measured by competitive ELISA method. After centrifugation, the supernatant of culture was collected. Before performing ELISA, the supernatant was diluted to lower protein concentration, depending on the protein concentration range of the standard curve, which was built with the commercialized rhFGF-2 (catalog number: 233-FB-025, R\&D system, Minneapolis, US) as the standard. The supernatant was immobilized to the wells of a 96-well plate overnight. Unbound protein was washed 3 times with PBS-T and blanks on the well surface were filled with $2 \%$ BSA (Sigma-Aldrich) incubated for an hour. Mouse antihuman FGF-2 IgG (Sigma-Aldrich) and anti-mouse horseradish peroxidase (Sigma-Aldrich) were used as primary and secondary antibodies, respectively. Afterwards, an addition of TMB (Thermo Fisher Scientific) was performed to react with horseradish peroxidase. This reaction was stopped by $\mathrm{HCl} 2 \mathrm{~N}$ (Scharlau, Barcelona, Spain). The concentration of rhFGF-2 was determined through the absorbance of the mixture at $450 \mathrm{~nm}$ by Multiskan Ascent (Thermo Fisher Scientific) and via the standard curve.

\section{Analysis of biological activity of rhFGF-2}

The bioactivity of FGF-2 was evaluated by its ability to stimulate the proliferation of NIH-3T3 cell line (ATCC), which has a number of FGF receptors on its cell surface. Based on NIH-3T3 cell numbers in culture medium, bioactivity of rhFGF-2 was compared with commercialized FGF-2 (catalog number: 233FB-025, R\&D system, Minneapolis, US) and negative control (without FGF-2 and without cell). The cell was cultured in DMEM/F12 without FBS (Sigma-Aldrich) and incubated with target protein for 36 hours. After this growth period, the cells were incubated with MTT solution (Sigma-Aldrich) for 4 hours to form insoluble formazan dye. After solubilization, the formazan dye was quantitated using Multiskan Ascent 


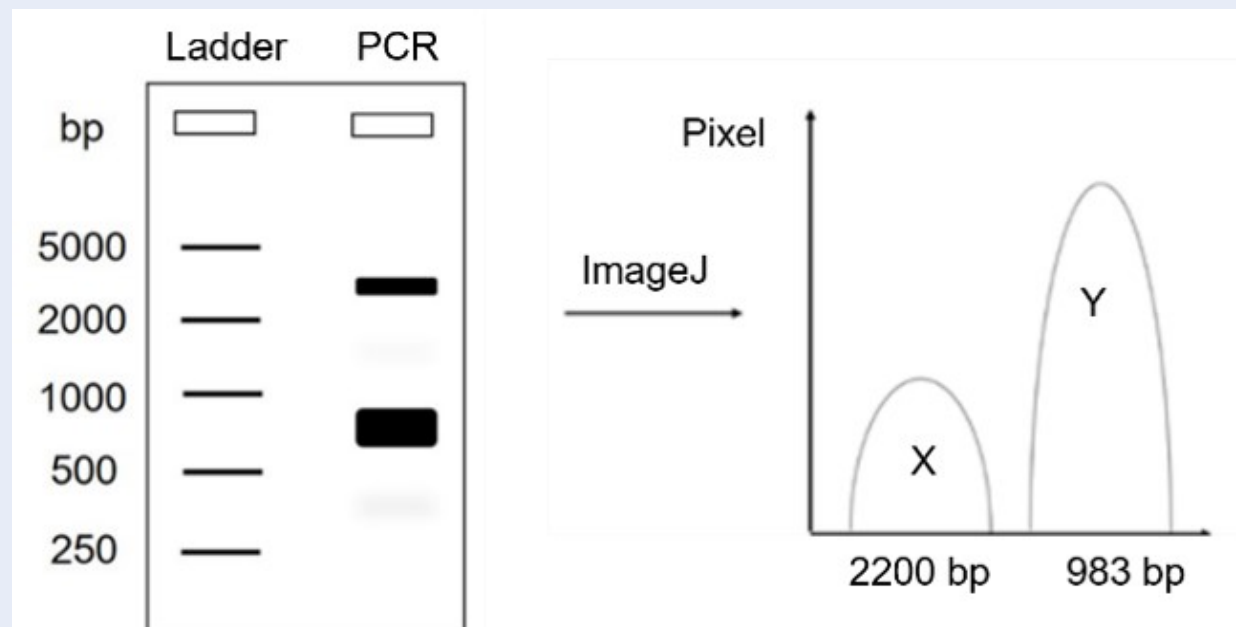

Figure 1: Illustration of indirect quantitative gene copy method by PCR and ImageJ. X, intensity of AOX1 gene band; $Y$, intensity of FGF-2 band.

A
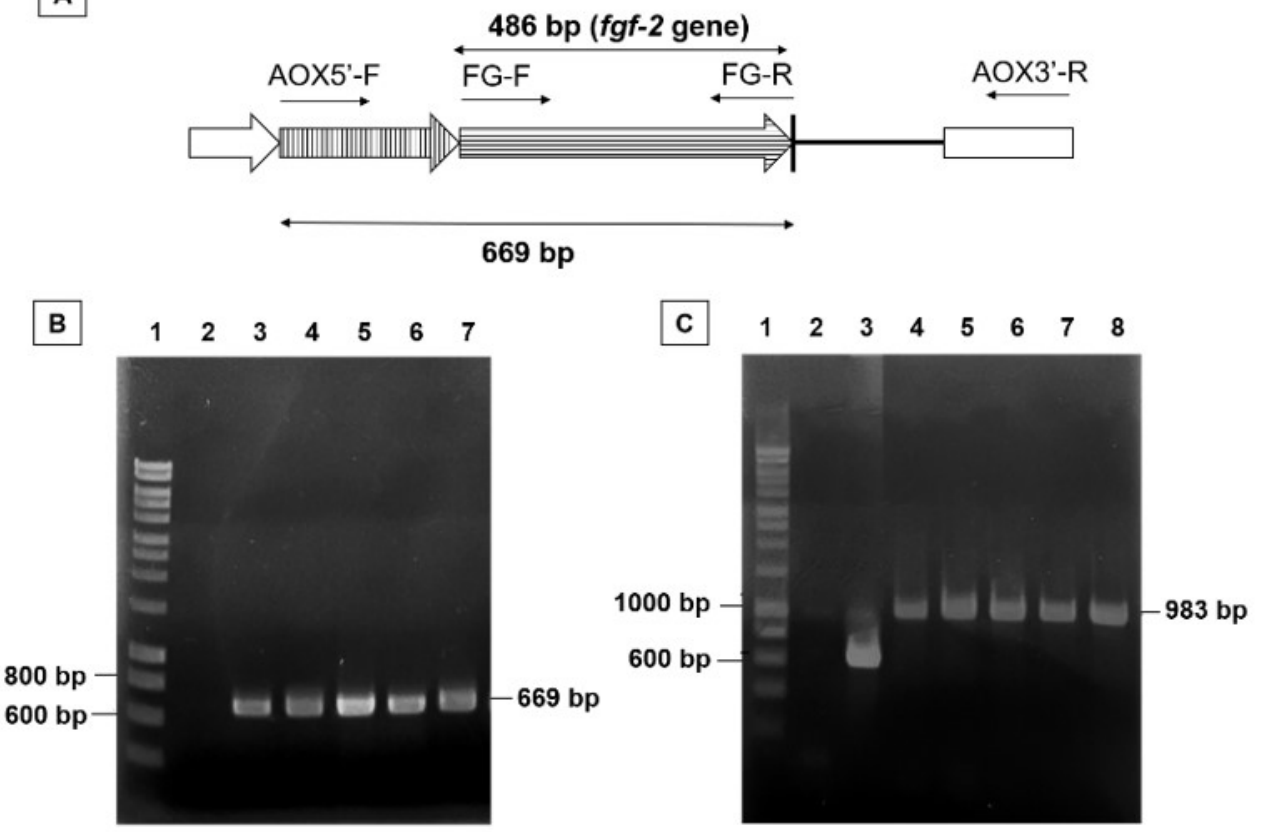

Figure 2: Construction of recombinant E. coli DH5 $\alpha$ carrying pPICZ $\alpha \mathbf{A} /$ fgf-2 plasmid. A, Schematic diagram of forward and reverse amplification primer sets; B, Result of PCR using primer set of FG-R and AOX-F, Lane 1: DNA ladder, Lane 2: Negative Control, Lane 3-7: 5 suspected colonies; C, Result of PCR using primer set of AOX-R and AOX-F, Lane 1: DNA ladder, Lane 2: Negative control, Lane 3: pPIC $\alpha$ A plasmid (513 bp), Lane 4-8: suspected pPICZ $\alpha \mathrm{A} / f g f-2$ plasmids. 
software. The measured absorbance directly correlates to the number of viable cells. This experiment was performed in triplicate, and the results were statistically analyzed by Graphpad Prism 6.0 software (GraphPad, Inc., CA, USA). The laboratory unit of proliferative bioactivity was calculated as follows:

$L U\left(\frac{u n i t}{n g}\right)=\frac{1 \times 10^{6}}{\operatorname{ED} 50\left(\frac{m g}{m l}\right)}$

\section{RESULTS}

\section{Construction of pPICZ $\alpha$ A/fgf-2 plasmid}

The gene encoding for FGF-2 was cloned into pPICZ $\alpha$ A plasmid by eClone kit based on homologous recombinant mechanism. The recombinant vector was transferred into E. coli DH5 $\alpha$. The successfully transformed host cells were selected based upon their ability to grow on the LB medium containing zeocin, followed by colony PCR to determine the presence of the $f g f-2$ insert. The plasmid was extracted from the positive clones and further confirmed for the presence of the $f g f-2$ gene; the direction of the $f g f$ 2 gene in the plasmid was confirmed by PCR with 2 different primer sets (Figure 2A). The PCR with the primer set of AOX5'-F and FG-R resulted in a single band of expected size for all 5 positive clones (Figure 2B). This implies that the $f g f-2$ gene was inserted after the AOX1 promoter and in the same orientation with the promoter. The PCR with the primer set of AOX5'-F and AOX3'-R was performed to make sure that only one copy number of $f g f-2$ gene was inserted (Figure 2B).

\section{Cloning of pPICZ $\alpha$ A/fgf-2 plasmid in P. pas- toris}

In this present study, the wild-type $P$. pastoris X33 was used for cloning. To enhance the homologous recombinant yield, pPICZ $\alpha \mathrm{A} / f g f-2$ plasmid was cut by SacI enzyme and then transferred into $P$. pastoris by electroporation. The positive transformants were selected through their ability to grow on YPD-zeocin medium and further subjected to colony PCR with $f g f-2$ primers in order to verify the presence of the $\mathrm{pPICZ} \alpha \mathrm{A} / f g f-2$ plasmid. The wildtype $P$. pastoris X33 and the pPICZ $\alpha \mathrm{A} / f g f-2$ plasmid were used as negative and positive control, respectively. The PCR results showed that there was a single 486 bp band corresponding to a unique band of the positive control (Figure 3A). It indicated that $P$. pastoris carrying $f g f-$ 2 gene was successfully cloned.

Afterwards, the genotype of these transformants were determined by PCR with the primer set of AOX5'-F and AOX3'-R. The PCR results of all transformants showed that there were two bands at $2.2 \mathrm{kbp}$ and 983 $\mathrm{bp}$, equivalent to the length of AOX1 gene and $f g f$ 2 gene with their own promoter, respectively. It revealed that all recombinant strains had additive insertion integration. Therefore, all strains were further determined for the $f g f-2$ gene copy number of each strain (Figure 3B). As the result of $f g f-2$ gene copy number quantification (Figure 3C), we succeeded in cloning multiple gene copy number of $P$. pastoris.

\section{Comparison of protein expression among different fgf-2 gene copy strains}

All strains were classified into three groups based on the copy number of $f g f-2$ gene: low copy strains (4-5 copies), medium copy strains (8-11 copies), and high copy strains (more than 20 copies). To investigate the effect of gene copy number variations on rhFGF2 protein expression, one transformant of each group was cultivated in $100 \mathrm{~mL}$ BMMY medium and induced by $0.5 \%$ methanol. The gene copy number of each group was as follows: 4 (low), 11 (medium), and 22 (high) copies. Every 24 hours, the biomass was collected to measure $\mathrm{OD}_{600 \mathrm{~nm}}$ and the supernatant was used to analyze rhFGF-2 expression by ELISA and SDS-PAGE. The results showed that all three strains had a common pattern of the growth curve (Figure 4). The highest OD $_{600 \mathrm{~nm}}$ reached 10-12 after 48 hours of cultivation. It indicated that the integrated gene copy number was not affected by the growth of this strain. Nevertheless, the expression levels among the 3 strains were considerably different (Figure 4). As the result, the expression level of the 4-copy strain increased slightly from 24 hours to the end of culture time. In contrast, the expression level of the 11-copy and the 22-copy strains dramatically decreased after 24 hours, despite the fact that growth was changed minimally. Moreover, the lowest copy strain reached a higher rhFGF-2 protein production than the others at 24, 48 and 72 hours, respectively. Consequently, this strain was selected to produce the rhFGF-2 protein, which later on would be studied further for the purification process and bioactivity assay.

\section{Purification and identification of rhFGF-2}

The P. pastoris X33::fgf-2 was cultivated in $200 \mathrm{~mL}$ BMMY at $30^{\circ} \mathrm{C}, 250 \mathrm{rpm}$ and induced by $0.5 \%$ methanol. After 72 hours, the culture supernatant was collected in order to purify the rhFGF-2 protein by heparin affinity chromatography. The target protein was eluted by using a gradient from 0 to $100 \%$ of Buffer B. The protein purity and yield of purification were determined by SDS-PAGE and ELISA, respectively. 

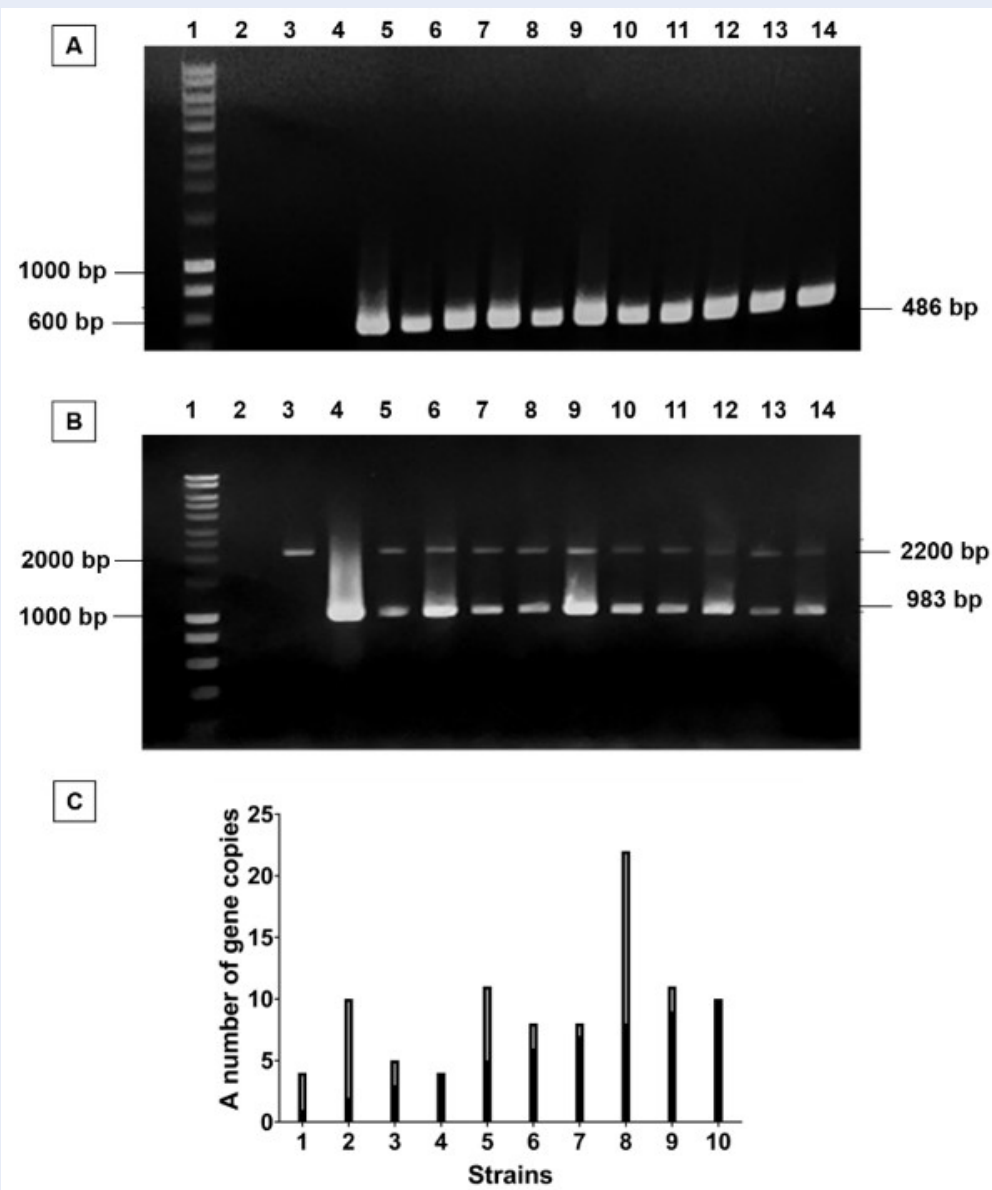

Figure 3: Cloning of pPICZ $\alpha$ A/fgf-2 plasmid into P. pastoris. A. Colony PCR results using FG-F/FG-R primers of transformants which grew on YPD-zeocine, Lane 1: DNA ladder, Lane 2: Negative control, Lane 3: P. pastoris X33, Lane 4, pPICZ $\alpha \mathrm{A} / f g f-2$ plasmid as positive control, Lane 5-14: transformants. B, PCR results using AOX-F/AOX$R$ primers of positive transformants which carries pPICZ $\alpha A / f g f-2$ plasmid, Lane 1: DNA ladder, Lane 2: Negative control, Lane 3: P. pastoris X33, Lane 4: pPICZ $\alpha$ A/fgf-2 plasmid, Lane 5-14: positive transformants. C, Specific fgf-2 gene copy number of all positive transformants.

As seen from the SDS-PAGE results, there were two bands between $14.4 \mathrm{kDa}$ and $20.1 \mathrm{kDa}$ in the $60 \%$ 90\%B eluted fraction (well 4-6, Figure 5). These fractions were further confirmed by Western blotting by specific antibody (well 9-11, Figure 5) and revealed that both bands were the rhFGF-2 protein. The upper band was predicted to be the glycosylated rhFGF2 protein.

The concentration of purified rhFGF-2 protein was qualified by ELISA based on the standard curve, and the purity was determined by Gel Analyzer software. The results showed that rhFGF-2 protein after purification reached $179.2 \mu \mathrm{g}$ per $200 \mathrm{~mL}$ culture (equivalent to $850 \mu \mathrm{g} / \mathrm{L}$ ) and the purity reached $98.8 \%$. The recovery was estimated as approximately $6.13 \%$.
In conclusion, the highly purified rhFGF- 2 protein obtained from $P$. pastoris X33::fgf-2 could accelerate the proliferation of mouse fibroblasts, equivalent to commercialized product, with laboratory units reaching $5.6-8.94 \times 10^{4}$ unit/ng.

\section{DISCUSSION}

In this study, the low copy number of target gene resulted in the highest expression level which was similar to previous studies of multi-copy strains, even though the growth of the host strain was not affected by the integrated gene copy number. Many studies have demonstrated that multiple copy number of integrated gene could improve the expression level of the target protein. However, when the optimum is reached, further increase can sometimes cause neg- 


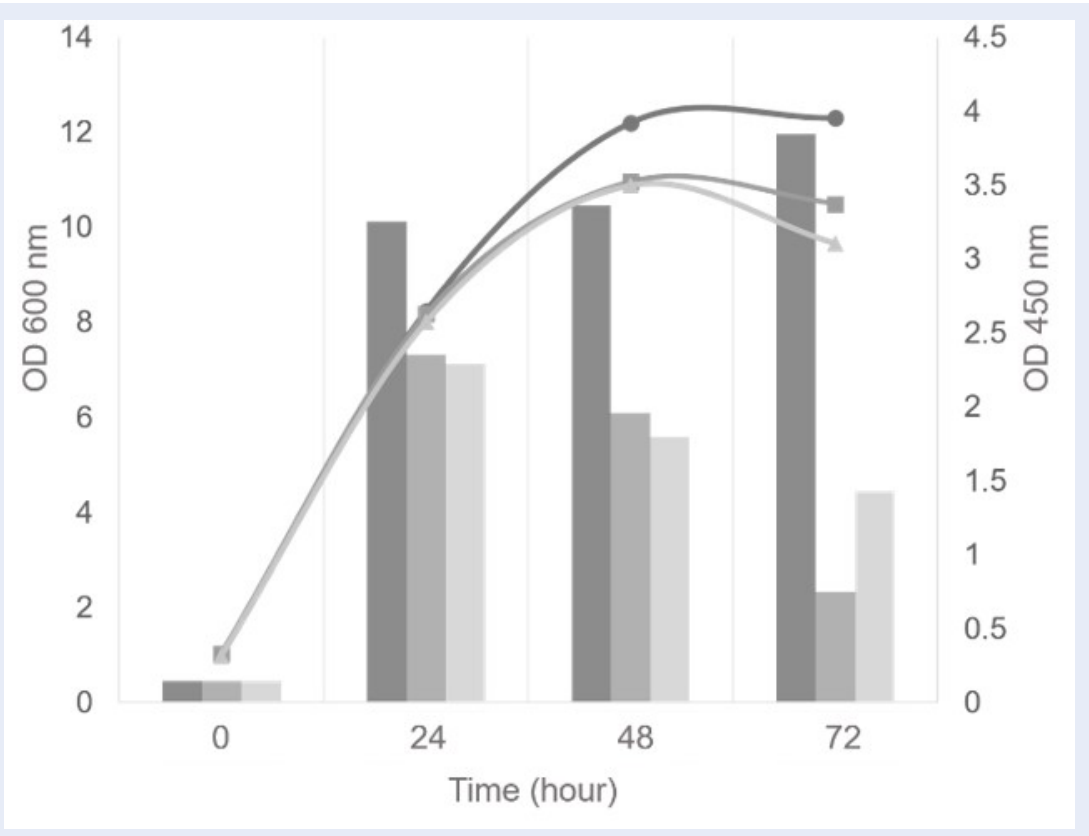

Figure 4: The growth and FGF-2 expression level of various fgf-2 gene copy number strains was evaluated by $\mathrm{OD}_{600}$ and ELISA. $\mathrm{OD}_{600}$ (line with dots) and $\mathrm{OD}_{450}$ (bar) were graphed as circle $(\bigcirc)$ and dark grey - 4 copies, rectangle $(\square)$ and medium grey -11 copies, triangle $(\triangle)$ and light grey - 22 copies, respectively. ELISA experiment was performed in triplicate.

ative effects $^{22,23}$. For instance, high copy $P$. pastoris strain might suffer from protein folding-related oxidative stress and insufficient supply of carbon and energy sources ${ }^{24}$.

As a result, the yield of FGF-2 protein in this study was lower than other expression systems in previous studies of $P$. pastoris ${ }^{9,21}$, where the culture condition was optimized for methanol concentration, $\mathrm{pH}$, and induction time. Therefore, the efficiency of the P. pastoris strain in this study could be improved by optimized shake-flask condition ${ }^{21}$ and be further enhanced in up-scale production, if dissolved oxygen, $\mathrm{pH}$, temperature and carbon source feeding strategy could be controlled ${ }^{19,25}$. In short, $P$. pastoris might be a promising strain for high yield production of FGF-2 protein.

On the other side, the ease of purification in P. pastoris with specific affinity chromatography might bring more benefits than other intracellular expression systems ${ }^{9,26}$, due to lower content of extracellular proteins secreted from the host cells. As compared with another study of FGF-2 expressed from P. pastoris ${ }^{21}$, the purification method of our study was better at reducing time and costs for downstream processes since we only performed one-step. The differences in results might be caused by the types of chromatography. Moreover, the recovery of purification in this study $(6.13 \%)$ was higher than in a previous study with same type of chromatography $(4.49 \%)^{10}$. This might be affected by differences of equilibration and washing buffer. Briefly, heparin affinity chromatography is a rationale choice with good potential for shortening the purification process.

After purification, two bands of FGF-2 protein were detected by Western blotting. The original FGF2 protein is a non-glycoprotein; nevertheless, natural glycosylation processing can occur at hydroxy groups of threonine and/or serine residues in protein inside yeast cells ${ }^{27}$. These amino acids were approximately $11.6 \%$ of the total peptide sequence of rhFGF-2 protein. Hence, we predicted that the upper band is glycosylated FGF-2 protein. The bioactivity of the mixture of glycosylated FGF-2 protein and nonglycosylated FGF-2 protein was demonstrated to be equivalent to commercialized FGF-2 protein, based on its ability to stimulate the proliferation of the NIH3T3 cell line. Therefore, glycosylation did not affect the bioactivity of the FGF-2 protein.

\section{CONCLUSIONS}

In short, our study was successful in cloning multiple copy of $f g f-2$ gene into Pichia pastoris strain. In comparison with other multiple copy $f g f-2$ gene strains, the 4-copy $f g f-2$ gene strain has the ability to express 


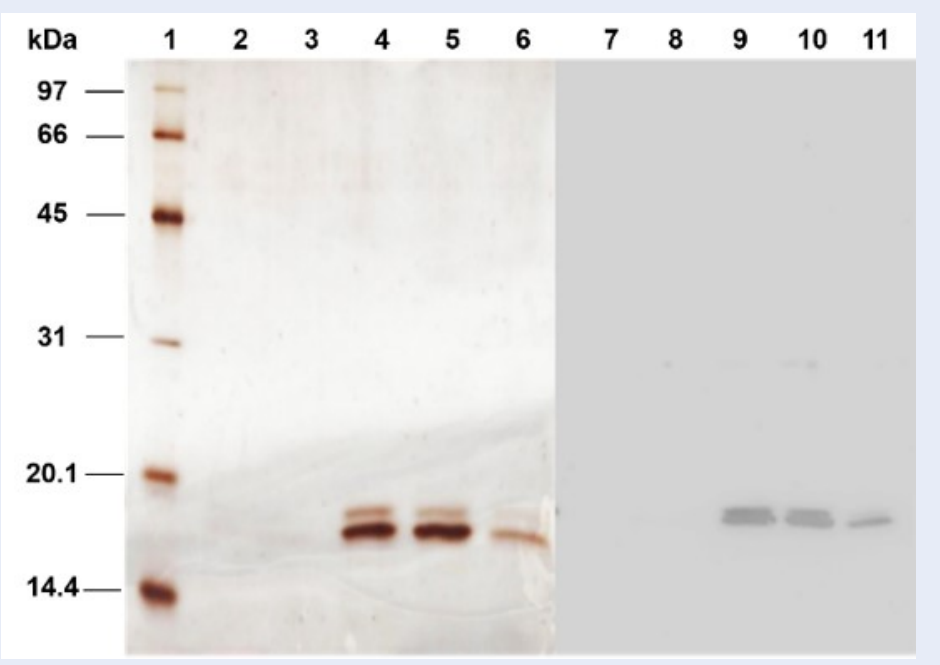

Figure 5: FGF-2 protein purification by heparin affinity chromatography using stepwise method. Lane 1: Protein ladder, Lane 2-6: SDS-PAGE result of eluted fraction at $50 \%, 60 \%, 70 \%, 80 \%$ and $90 \%$ of Buffer B, respectively, Lane 7-11: Western Blotting result of eluted fraction at $50 \%, 60 \%, 70 \%, 80 \%$ and $90 \%$ of Buffer B, respectively.

Table 1: Bioactivity comparison of rhFGF-2 from P. pastoris and commercialized FGF-2

\begin{tabular}{lccc}
\hline Criteria & FGF-2 from P. pastoris & Commercialized FGF-2 & p-value \\
ED50 (ng/ml) & $14.52 \pm 3.34$ & $20.80 \pm 3.60$ & 0.6619 \\
Hill Slope & $1.202 \pm 0.3196$ & $1.689 \pm 0.415$ & 0.0566 \\
R2 & 0.9048 & 0.9577 & - \\
LU (unit/mg) & $5.6-8.94 \times 104$ & $4.10-5.81 \times 104$ & - \\
\hline
\end{tabular}

Experimental value was represented as Mean \pm SEM.

the highest level of rhFGF-2 protein. The concentration of purified rhFGF- 2 reached $179.2 \mu \mathrm{g}$ per $200 \mathrm{~mL}$ of shake-flask culture (equivalent to $850 \mu \mathrm{g} / \mathrm{L}$ ), with 98.8\% purity after 1-step heparin affinity chromatography. In addition, the rhFGF- 2 protein showed similar biological activity on the NIH/3T3 cell line as commercialized FGF-2 protein.

\section{LIST OF ABBREVIATIONS USED}

AOX1: Aldehyde Oxidase 1

BMMY: Buffer Methanol-Complex Medium bpP: Base pair

E. coli: Escherichia coli

ELISA: Enzyme-linked immunosorbent assay

fgf-2: Fibroblast Growth Factor-2

kDa: Kilo Dalton

LB: Luria Broth

OD: Optical Density

PAGE: Polyacrylamide Gel Electrophoresis

P. pastoris: Pichia pastoris

PCR: Polymerase Chain Reaction

SDS: Sodium Dodecyl Sulfate
SDS-PAGE: Sodium Dodecyl Sulfate - Polyacrylamide Gel Electrophoresis

YPD: Yeast extract - Peptone - Dextrose medium

\section{ACKNOWLEDGEMENTS}

This work was supported by VNUHCM - University of Science research project funding, Laboratory of Molecular Biotechnology and Department of Molecular and Environmental Biotechnology infrastructure of VNUHCM - University of Science.

\section{AUTHOR'S CONTRIBUTION}

This study was designed by Nguyen Hieu Nghia. Nguyen Cao Kieu Oanh contributed on data collection. Data analysis and interpretation for the work were carried out by Nguyen Hieu Nghia, Nguyen Cao Kieu Oanh and Le Kha Han. Nguyen Tri Nhan drafted the article and Le Kha Han wrote it. The article was critically revised and approved to be published by Nguyen Tri Nhan. 


\section{CONFLICTS OF INTEREST}

All author declare that they have no conflicts of interest.

\section{REFERENCES}

1. Nagai $H$, Tsukuda R, Mayahara HJB. Effects of basic fibroblast growth factor (bFGF) on bone formation in growing rats. 1995;16(3):367-373. Available from: https://doi.org/10.1016/ 8756-3282(94)00049-2.

2. Rabchevsky A, Fugaccia I, Turner A, Blades D, Mattson M, $\mathrm{n}$ Scheff SJE. Basic fibroblast growth factor (bFGF) enhances functional recovery following severe spinal cord injury to the rat. 2000;164(2):280-291. PMID: 10915567. Available from: https://doi.org/10.1006/exnr.2000.7399.

3. Park CM, b Hollenberg MJJD. Basic fibroblast growth factor induces retinal regeneration in vivo. 1989;134(1):201-205 Available from: https://doi.org/10.1016/0012-1606(89)900894.

4. Murakami S, Takayama S, Ikezawa K, Sltimabukuro Y, Kitamura M, Nozaki T, et al. Regeneration of periodontal tissues by basic fibroblast growth factor. 1999;34(7):425-430. Available from: https://doi.org/10.1111/j.1600-0765.1999.tb02277. xPMid:10685372.

5. McGee GS, Davidson JM, Buckley A, Sommer A, Woodward SC, Aquino $A M$, et al. Recombinant basic fibroblast growth factor accelerates wound healing. 1988;45(1):145-153. Available from: https://doi.org/10.1016/0022-4804(88)90034-0.

6. Schweigerer L, Neufeld G, Friedman J, Abraham JA, Fiddes JC, Gospodarowicz DJN. Capillary endothelial cells express basic fibroblast growth factor, a mitogen that promotes their own growth. 1987;325(6101):257. Available from: https://doi.org/ 10.1038/325257a0PMid:2433585.

7. Faham S, Hileman R, Fromm J, Linhardt R, Rees DJS. Heparin structure and interactions with basic fibroblast growth factor. 1996;271(5252):1116-1120. PMID: 8599088. Available from: https://doi.org/10.1126/science.271.5252.1116.

8. Yayon A, Klagsbrun M, Esko JD, Leder P, Ornitz DMJC. Cell surface, heparin-like molecules are required for binding of basic fibroblast growth factor to its high affinity receptor. 1991;64(4):1-8. Available from: https://doi.org/10.1016/00928674(91)90512-W.

9. Gasparian M, Elistratov P, Drize N, Nifontova I, Dolgikh D, Kirpichnikov MJB. Overexpression in Escherichia coli and purification of human fibroblast growth factor (FGF-2). 2009;74(2):221-225. PMID: 19267679. Available from: https: //doi.org/10.1134/S000629790902014X.

10. An N, Ou J, Jiang D, Zhang L, Liu J, Fu K, et al. Expression of a functional recombinant human basic fibroblast growth factor from transgenic rice seeds. 2013;14(2):35563567. PMID: 23434658. Available from: https://doi.org/10. 3390/ijms14023556.

11. Wu X, Kamei K, Sato H, i Sato S, Takano R, Ichida M, et al. Highlevel expression of human acidic fibroblast growth factor and basic fibroblast growth factor in silkworm (Bombyx mori L.) using recombinant baculovirus. 2001;21(1):192-200. PMID: 11162406. Available from: https://doi.org/10.1006/prep.2000. 1358.

12. Soleyman MR, Khalili M, Khansarinejad B, Baazm MJIRCMJ. High-level expression and purification of active human FGF-2 in Escherichia coli by codon and culture condition optimization. 2016;18(2). PMID: 27175305. Available from: https: //doi.org/10.5812/ircmj.21615.

13. Cereghino JL, Cregg JM. Heterologous protein expression in the methylotrophic yeast Pichia pastoris. Fems microbiology reviews. 2000;24(1):45-66. PMID: 10640598. Available from: https://doi.org/10.1111/j.1574-6976.2000.tb00532.x.

14. Ahmad M, Hirz M, Pichler H, Schwab HJ. Protein expression in Pichia pastoris: recent achievements and perspectives for heterologous protein production. 2014;98(12):5301-5317. PMID 24743983. Available from: https://doi.org/10.1007/s00253014-5732-5.

15. Klinner U, Schäfer B. Genetic aspects of targeted insertion mutagenesis in yeasts. 2004;28(2):201-223. PMID: 15109785. Available from: https://doi.org/10.1016/j.femsre.2003.10.002.

16. Nordén K, Agemark M, Danielson JÅ, Alexandersson E, Kjellbom PM, Johanson UJ. Increasing gene dosage greatly enhances recombinant expression of aquaporins in Pichia pastoris. 2011;11(1):47. PMID: 21569231. Available from: https: //doi.org/10.1186/1472-6750-11-47.

17. Athmaram $T$, Saraswat $S$, Singh AK, Rao MK, Gopalan $N$, Suryanarayana $V$, et al. Influence of copy number on the expression levels of pandemic influenza hemagglutinin recombinant protein in methylotrophic yeast Pichia pastoris. 2012;45(3):440-451. PMID: 22940846. Available from: https: //doi.org/10.1007/s11262-012-0809-7.

18. Mansur M, Cabello $C$, Hernández L, País J, Varas L, Valdés $J$, et al. Multiple gene copy number enhances insulin precursor secretion in the yeast Pichia pastoris. 2005;27(5):339345. PMID: 15834796. Available from: https://doi.org/10.1007/ s10529-005-1007-7.

19. Markošová $K$, Weignerova $L$, Rosenberg $M$, Křen $V$, Rebroš M. Upscale of recombinant $\alpha$-L-rhamnosidase production by Pichia pastoris MutS strain. 2015;6(1140). PMID: 26539173. Available from: https://doi.org/10.3389/fmicb.2015.01140.

20. Huang CJ, Damasceno LM, Anderson KA, Zhang S, Old LJ, Batt $C A$, et al. A proteomic analysis of the Pichia pastoris secretome in methanol-induced cultures. 2011;90(1):235-247. PMID: 21305280. Available from: https://doi.org/10.1007/s00253011-3118-5.

21. Mu X, Kong N, Chen W, Zhang T, Shen M, Yan W. High-level expression, purification, and characterization of recombinant human basic fibroblast growth factor in Pichia pastoris. Protein Expression and Purification. 2008;59(2):282-288. PMID: 18378165. Available from: https://doi.org/10.1016/j.pep.2008 02.009 .

22. Abad S, Kitz K, Hörmann A, Schreiner U, Hartner FS, Glieder AJ. Real-time PCR-based determination of gene copy numbers in Pichia pastoris. 2010;5(4):413-420. PMID: 20349461. Available from: https://doi.org/10.1002/biot.200900233.

23. Zhu T, Guo M, Tang Z, Zhang M, Zhuang Y, Chu J, et al. Efficient generation of multi-copy strains for optimizing secretory expression of porcine insulin precursor in yeast Pichia pastoris. 2009;107(3):954-963. PMID: 19486418. Available from: https://doi.org/10.1111/j.1365-2672.2009.04279.x.

24. Zhu T, Guo M, Zhuang Y, Chu J, Zhang SJ. Understanding the effect of foreign gene dosage on the physiology of Pichia pastoris by transcriptional analysis of key genes. 2011;89(4):1127-1135. PMID: 20981418. Available from: https://doi.org/10.1007/s00253-010-2944-1.

25. Markošová K, Camattari A, Rosenberg M, Glieder A, Turner NJ, Rebroš MJ. Cloning and upscale production of monoamine oxidase N (MAO-N D5) by Pichia pastoris. 2018;40(1):127133. PMID: 29019030 . Available from: https://doi.org/10.1007/ s10529-017-2450-y.

26. Sheng Z, Chang SB, Chirico WJ. Expression and purification of a biologically active basic fibroblast growth factor fusion protein. Protein Expression and Purification. 2003;27(2):267271. Available from: https://doi.org/10.1016/S1046-5928(02) 00601-0.

27. Gemmill TR, Trimble RB. Overview of $\mathrm{N}$-and O-linked oligosaccharide structures found in various yeast species. 1999;1426(2):227-237. Available from: https://doi.org/10. 1016/S0304-4165(98)00126-3. 